\title{
La oposición al franquismo en las sentencias del TOP: Organizaciones políticas y movimientos sociales
}

\author{
Sara Nuñez de Prado Clavell y Raúl Ramirez Ruiz \\ Universidad Rey Juan Carlos \\ sara.clavell@urjc.es \\ raul.ramirez@urjc.es
}

Recibido: 21/06/12

Aceptado: 10/06/2013

\section{RESUMEN}

Este artículo profundiza en el estudio de las organizaciones políticas y los movimientos sociales e ideológicos que protagonizaron la oposición al franquismo y que fueron considerados por las autoridades del régimen lo suficientemente peligrosos como para ser perseguidos y encausados.

Palabras clave: TOP, franquismo, movimientos sociales, oposición, delitos.

\section{The Opposition to the Franco's Regime in the Sentences of the TOP: Political Organizations and Social Movements}

\begin{abstract}
This article go into details about the study of the political organizations and the social and ideological movements that were responsible in the opposition to the Franco's regime and that were considered by the authorities of the regime it sufficiently dangerous as for be chased and accused.
\end{abstract}

Key words: Franco's Regime, Social Movements, Opposition, Crimes.

Sumario: Introducción. 1. Contexto situacional. 2. Nacimiento, actuación y significación del TOP 3. Los movimientos opositores: obreros, universitarios y nacionalistas. 4. Retrato de la oposición sentenciada por el tribunal de orden público. 4.1. Las organizaciones políticas de la izquierda comunista. 4.2. El socialismo y el anarquismo. 4.3 Los nacionalismos. 4.4 La oposición universitaria. 5. Comparativa de resultados con estudios previos. 6 . Conclusiones. 


\section{Introducción}

Para cualquier estudio relacionado con el Tribunal de Orden Público (TOP) es una consulta de partida obligada la investigación realizada por Juan José del Águila ${ }^{1}$. Esta obra básica recoge y analiza el $97 \%$ de las sentencias publicadas por el Tribunal, pero su pieza clave del análisis no es un estudio en profundidad de los contenidos de las sentencias, sino una descripción total de las mismas, con el objetivo de conseguir la reivindicación de todas y cada una de las víctimas de la represión franquista que fueron enjuiciadas por el Tribunal ${ }^{2}$.

La contribución novedosa del trabajo que aquí se presenta reside en la metodología empleada, ya que se ha partido de un objeto de estudio muy definido, como es el de la consideración del delito específico en el conjunto de la sentencia. En los trabajos hasta ahora publicados sobre las actividades del TOP, la metodología empleada se centraba en el análisis de todas las sentencias de manera globalizadora. En cambio, en esta investigación se ha partido, no sólo de una selección aleatoria de las mismas, sino que también se ha procedido a un análisis de contenido pormenorizado que ha permitido separar los que eran delitos con adscripción política real, de aquellos que si bien eran enjuiciados por el TOP debido a su naturaleza, no estaban encuadrados en ningún movimiento o incluso no tenían ninguna motivación política. Esta especie de confusión en torno a los delitos, como se verá a lo largo del artículo, suele encontrarse en cuestiones como la tenencia ilícita de armas o los desórdenes públicos, que en la mayoría de las ocasiones no eran políticos sino que estaban relacionados con el hampa. Algo parecido ocurre con el delito de injurias al Jefe del Estado, muchas veces proferidas por borrachos durante sus delirios alcohólicos y que en el fondo no tenían ninguna connotación política real.

La razón de la selección aleatoria de las sentencias ha venido dada por la necesidad de contar con una muestra cuantitativamente manejable (se ha recopilado el 10\% del total de las sentencias) y a la vez representativa de todo el periodo que permitiese el análisis en profundidad, pero siempre sin desvirtuar las conclusiones que se obtuviesen del mismo. Para ello se han escogido años alternos (1964, 1966, 1967³ 1969 , 1971, 1973, 1974 y 1976). En total se analizaron 348 sentencias $^{4}$ que equivalen a 493 delitos y que cumplen con el requisito de estar por debajo del $5 \%$ de no fiabili$\mathrm{dad}^{5}$. De esta manera, el componente de la aleatoriedad se convirtió en un elemento

1 DEL ÁGUILA, Juan José: El TOP. La represión de la Libertad, Barcelona, Planeta, 2001.

2 Por este motivo de reivindicación de la memoria en las últimas 111 páginas de su obra se recogen los nombres de todos los protagonistas del TOP, abogados, procuradores y procesados.

3 Los libros de sentencias del año 1968 están incompletos por lo que se decidió seleccionar el año 1967.

4 Esta metodología ya ha sido probada con éxito en trabajos anteriores, por ejemplo: RAMÍREZ RUIZ, Raul: "La criminalidad como fuente histórica", Anuario de derecho Penal y Ciencias Penales, Madrid, 60/1 (2007), pp. 379-405. Y otra metodología paralela, pero con el mismo instrumento de la criminalidad como fuente para la historia, es la puesta práctica en el trabajo de FERNÁNDEZ ASPERILLA, Ana: "Franquismo, delincuencia y cambio social" Espacio, tiempo y forma, Madrid, Serie V, Historia Contemporánea, 17 (2005), pp. 297-309.

5 En investigación social las muestras probabilísticas necesitan cumplir cuatro requisitos: un esquema muestral que permita enumerar las unidades del universo; un procedimiento de selección aleatorio, la fijación de una probabilidad de error muestral (se aceptan los valores que oscilan entre $1 \%$ y $5 \%$ ); y una estimación 
fundamental de esta investigación, ya que ha permitido centrar el foco de estudio en el delito como tal, lo que también resulta novedoso ya que las conclusiones de otros autores se basaban de manera general en la sentencia y no en el delito ${ }^{6}$.

La utilización de dicha muestra representativa ha tenido, además, la ventaja de que, desde la perspectiva del historiador, ha permitido sumergirse en la descripción del caso, con el fin de descubrir los detalles y ahondar en las circunstancias del delito que se juzgaba. Y desde la perspectiva de la política, ha puesto de manifiesto la existencia de contenidos de propaganda incluidos por los jueces en sus fallos.

Esta forma de abordar la investigación ha facilitado, por tanto, la posibilidad de aislar aquella información que era la relevante para trazar no sólo el alcance y la trayectoria de los movimientos sociales de oposición al franquismo, sino sobre todo para conocer cuándo y por qué a dichos movimientos se les consideró una amenaza para el régimen. Por lo demás, el hecho de centrase sólo en el delito enjuiciado y no en la sentencia en su conjunto, ha servido también para profundizar en dichos movimientos de oposición desde la óptica del propio franquismo, perspectiva que hasta ahora tampoco había sido muy estudiada. En definitiva, esta forma de acercamiento al contenido delictivo de la sentencia ha colocado dichos movimientos frente a las dos caras del mismo espejo: la de las acciones propias de dicha oposición, justificadas desde su propia ideología y la visión que desde las autoridades franquistas se tenía de las mismas.

\section{Contexto situacional de la creación y desarrollo del TOP}

El General Franco creó un régimen basado en dos sólidos principios ideológicos que se situaban por encima de los demás: la unidad de la nación y el catolicismo. Por debajo de ellos existían otros elementos que, si bien según el momento histórico concreto pudieron actuar como pilares del régimen, cuando las circunstancias lo demandaban podían quedarse en la periferia del mismo. Entre ellos cabe citar al falangismo o al nacionalsindicalismo. Asimismo, el franquismo fue sustentado por el Ejército (sobre todo en los primeros tiempos), la Iglesia (aunque al final se volvió muy crítica con el régimen) y el Movimiento Nacional o partido único, que cada vez se separó más de los presupuestos ideológicos falangistas que le habían otorgado su razón de ser. Los motivos de la existencia de ese escaso entramado ideológico, además de la propia personalidad del Caudillo, un militar con no demasiada formación intelectual pero con una alta facultad de control y mando, se debieron fundamentalmente a la capacidad de adaptación que tuvo el propio régimen, que sin tocar sus fundamentos básicospodía reescribir su guión de funcionamiento según le demandaban las circuns-

de la heterogeneidad del universo. Este estudio cumple estos cuatro principios (www.psico.uniovi.es/REMA/ $\mathrm{v} 3 \mathrm{n} 1 / \mathrm{a} 1 / \mathrm{p} 3 . \mathrm{html}$

6 Por ejemplo, la detallada investigación de ROLDÁN BARBERO, Horacio: El maoísmo en España y el Tribunal de Orden Público (1964-1976), Córdoba, Universidad de Córdoba, 2010. También el trabajo sobre el antifranquismo catalán realizado por TÉBAR, Javier (Coord.). Topcat 1963-1977: L'antifranquisme català davant el Tribunal de Orden Público [en línea] Barcelona, Fundació Cipriano García de CCOO de Catalunya, 2010. Disponible en: http://www.ccoo.cat/revistes/arxiu/topcat.pdf 
tancias ${ }^{7}$. Así, la necesidad de sobrevivir en un entorno internacional básicamente democrático y la propia evolución social interna, obligaron al régimen a tomar una actitud más moderada y a crear instituciones que le permitiesen presentar una apariencia de apertura y modernidad que realmente no existía. Además, iniciados los años 60 , con la finalidad de hacerse ese hueco necesario en el entramado internacional, España solicitó su ingreso en la Comunidad Económica Europea (CEE). Solicitud que si bien le fue denegada por no cumplir con la exigencia de ser un régimen democrático, sí le sirvió poco tiempo después culminar una serie de acuerdos económicos con la CEE, cuestión que era la que en el fondo buscaba el gobierno.

Ahora bien, a la vez que se desarrollaba ese proceso de acercamiento a Europa, el régimen debió hacer frente a una campaña negativa de dimensión internacional que surgió a raíz del llamado "contubernio de Múnich" ", en donde la oposición al franquismo se mostró públicamente contraria a que se aceptase la solicitud española de ingreso en la CEE. En la Resolución del Congreso del Movimiento Europeo, como se denominó realmente el bautizado por los periódicos como "contubernio de Múnich", se explicaron las razones por las que España no debía integrarse en la Europa comunitaria:

El Congreso del Movimiento Europeo, reunido en Múnich los días 7 y 8 de junio de 1962, estima que la integración, ya en forma de adhesión, ya de asociación de todo país a Europa, exige de cada uno de ellos instituciones democráticas, lo que significa en el caso de España, de acuerdo con la Convención Europea de los Derechos del Hombre y la Carta Social Europea, lo siguiente:

La instauración de instituciones auténticamente representativas y democráticas que garanticen que el gobierno se basa en el consentimiento de los gobernados.

La efectiva garantía de todos los derechos de la persona humana, en especial los de libertad personal y de expresión, con supresión de la censura gubernativa.

El ejercicio de las libertades sindicales sobre bases democráticas y de la defensa por los trabajadores de sus derechos fundamentales, entre otros medios por el de la huelga.

\footnotetext{
7 Magnífico ejemplo de esta adaptabilidad del Régimen fue precisamente la creación del TOP, tribunal que se formó como respuesta al Informe de la Comisión Internacional de Justicia, hecho público en 1962 y en el que se criticaba la situación del "Imperio de la Ley en España". Para este tema es interesante la obra de SESMA LANDRIN, Nicolás: "Franquismo, ¿Estado de derecho? Notas sobre la renovación del lenguaje político de la dictadura durante los años 60", Pasado y Memoria. Revista de Historia Contemporánea, Alicante, 5, (2006): pp. 51-57. También los trabajos de NUÑEZ DE PRADO, Sara: Los servicios de Información y propaganda en la guerra civil española, Madrid, UCM, 1992 y NUÑEZ DE PRADO, Sara: Las armas ideológicas de Franco, Madrid, Salisbury, 2013.

8 La importancia que "la reunión de Múnich" tuvo para el Régimen queda reflejada en una de las primeras sentencias del TOP con motivo, precisamente, del viaje a Múnich del que había sido uno de los ideólogos del régimen, Dionisio Ridruejo, quien fue juzgado por el delito de Propagandas ilegales en 1964. La sentencia de dicho proceso comienza así: "Probado y así se Declara que el inculpado Dionisio Ridruejo Jiménez, de buena conducta, procesado por delito de propaganda ilegal (en sumarios de 1956 y 1957 en los Juzgado 23 y 19 de Madrid) sobreseídos con aplicación del indulto de 31 de octubre de 1958, salió de España, sin la preceptiva documentación, a primeros de junio de 1962, dirección Múnich, atravesando la frontera por Puigçerdá con el fin de asistir al Congreso del Movimiento Europeo. Asimismo ha publicado un libro, cuyo título es: "Escrito en España, Cristal del Tiempo", editado por Losada S.A. en Buenos Aires, con fecha 14 de mayo de 1962; un artículo: "Múnich, un Hecho"; en París en 20 de junio de dicho año; otro, "La guerra continuada", aparecido en el periódico Le Monde", de la capital francesa, aparecido el 24 de abril de 1963 y un folleto titulado “España 1963”.... Sent. 29, 24 de Junio de 1964, AAPM-TOP, LS 1964-I.
} 
La posibilidad de organización de corrientes de opinión y de partidos políticos con el reconocimiento de los derechos de la oposición ${ }^{9}$.

Internamente tampoco el régimen lo tenía fácil. 1962 fue un año especialmente duro en cuanto al aumento visible de la protesta social y a su consiguiente represión. Y todo ello en un momento en el que el régimen, si quería ver culminadas sus aspiraciones internacionales, debía maquillar su situación interna para darle una mayor apariencia democrática.

Es precisamente en este contexto de necesidad de adaptación a las exigencias internacionales como surgió el Tribunal de Orden Público (TOP), ya que como detalladamente recoge Juan José del Águila, en la gestación del TOP está la necesidad de sustraer de la jurisdicción militar ciertos delitos políticos con el fin de dar a la justicia española un enfoque menos militar y un aspecto más civilizado, dictando condenas más leves en el marco de una jurisdicción penal civil ${ }^{10}$.

\section{Nacimiento, actuación y significación del TOP}

El TOP, con sede en Madrid y compuesto por un Presidente, dos magistrados, un fiscal y un secretario, fue creado por la Ley 154/63 de 2 de diciembre de 1963. Según establecía dicha ley,

tenía competencia privativa para conocer de los delitos cometidos en todo el territorio nacional, singularizados por la tendencia en mayor o menor gravedad a subvertir los principios básicos del Estado, perturbar el orden público o sembrar la zozobra en la conciencia nacional.

Pasaban también a su jurisdicción las atribuciones del Tribunal Especial de Masonería y Comunismo que existía desde 1940 y que desapareció en 1964. Consecuentemente con lo anterior, el TOP podía juzgar los siguientes delitos: contra la seguridad exterior del Estado, Jefe del Estado, las Cortes, Consejo de Ministros y forma de gobierno; delitos de rebelión, sedición, desórdenes públicos o propagandas ilegales. Y siempre que obedecieran a un móvil político o social, también se incluían entre su competencias los delitos de detención ilegal, sustracción de menores, allanamiento de morada, amenazas y coacciones. Igualmente pasaban a su jurisdicción los delitos de descubrimiento y revelación de secretos, siempre que la jurisdicción militar se inhibiera de ellos. Se incluían los delitos conexos y las faltas incidentales de todos los delitos anteriormente mencionados. A finales de 1972 (Decreto1314/72) se creó el Juzgado de Orden Público ${ }^{\circ} 2$, como consecuencia del crecimiento de los procedimientos incoados y del aumento de sus competencias al incluirse dentro de éstas el delito de tenencia ilícita de armas.

9 MADARIAGA, Salvador: España, Ensayos de Historia Contemporánea, Madrid, Espasa Calpe, 1978, pp. $542-543$

10 DEL ÁGUILA, Juan José: El TOP... 
Una vez desaparecido el régimen de Franco e iniciado el proceso de transición, el TOP perdió toda razón de ser, por lo que fue suprimido mediante Real Decreto Ley de 4 de enero de 1977 coincidiendo con la Ley de Reforma Política y la puesta en marcha de la Audiencia Nacional. Junto a él desaparecieron los Juzgados de Orden Público 1 y 2, pasando sus competencias a los Juzgados de Instrucción 21 y 22 de la Audiencia Provincial de Madrid.

En definitiva, el Tribunal de Orden Público nació como un tribunal especial creado para reprimir toda forma de oposición política o sindical y cuyo número de causas aumentó conforme lo hacía la actividad opositora a la dictadura.

\section{Los movimientos opositores: obreros, universitarios y nacionalistas}

La dictadura del general Franco hubo de hacer frente a una oposición interna que evolucionó en paralelo a la sociedad española y que encontró acomodo en ella ${ }^{11}$. De la inicial oposición de las fuerzas frentepopulistas derrotadas en la Guerra Civil, se pasó a otra nueva que a mediados de los sesenta evolucionó desde una adscripción mayoritariamente obrera a otra estudiantil y nacionalista. O dicho de otro modo, pasó de ser una oposición puramente izquierdista y proletaria, hasta otra potenciada por la naciente mesocracia que también se verá impulsada por la Iglesia católica y hará tomar conciencia a los sectores "más avisados" del Régimen de la necesidad de variar su estrategia si querían evitar una ruptura total con el franquismo tras la muerte del dictador.

Ahora bien, esa descripción generalizada e incluso simplista de la oposición, aunque no por ello menos real, no aporta demasiado a no ser que se complete con el conocimiento de cuáles eran, por una parte, los grupos más activos, y por otra, aunque en íntima relación con el punto anterior, cuáles eran los que más preocupaban al régimen y subsiguientemente los más perseguidos. La respuesta a ello la ofrece, precisamente, el estudio de los delitos enjuiciados por el TOP. A nivel general, de sus sentencias se deduce que en primer lugar preocupaba la oposición de extracción obrera, seguida por la nacionalista. A continuación se situaba la universitaria. Ello queda de manifiesto en la figura 1 en la que el $53 \%$ de los delitos se encuadran en la oposición protagonizada por las clases obrera, seguida a mucha distancia por la nacionalista ${ }^{12}$ con un $23 \%$ y quedando también muy atrás la universitaria, con un $15 \%$. Se ha añadido un $9 \%$ más que corresponde a delitos considerados de oposición, como son los de injurias al Jefe del Estado, en los que, aún considerándose contrarios al régimen, no se ha determinado claramente una adscripción ideológica o social determinada. Y han quedado fuera de la gráfica todas aquellas sentencias analizadas en las que no se ha encontrado motivación política alguna, sino que correspondían a delitos

11 Una perspectiva distinta y novedosa sobre este tema la presenta YSÀS, Pere: Disidencia y subversión. La lucha del Régimen Franquista por su supervivencia, 1960-1975, Barcelona, Crítica, 2004, p. 123. Como muy bien apunta el autor, para la dictadura “... la oposición organizada... era simplemente subversión y frente a ella no cabía... otra política que la represiva".

12 En este grupo el protagonismo lo tiene el nacionalismo vasco y más específicamente la banda terrorista ETA. 
comunes y que suponen un $16 \%$ del total. Suelen ser, como ya se comentó, sentencias sobre temas relacionados con la incautación de armas dentro del hampa urbana y con el delito de desórdenes públicos, entre los que se incluyen cuestiones como el robo del hilo de cobre o similares.

Fig. 1. Movimientos sociales protagonistas de la oposición al franquismo.

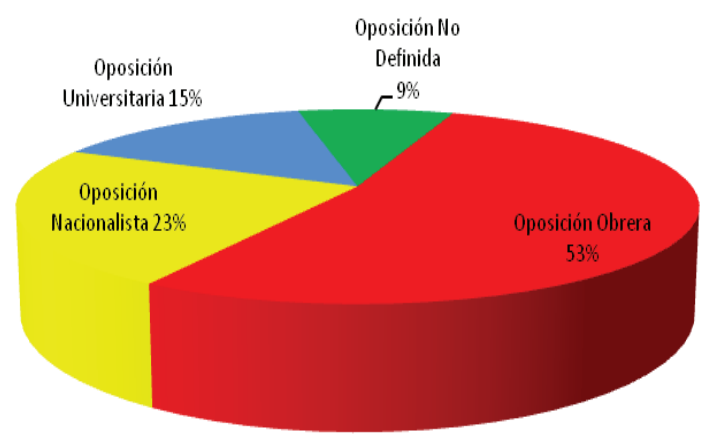

Fuente: Libros de Sentencias del Tribunal de Orden Público. Elaboración Propia

Por lo que respecta a la evolución diacrónica de los delitos relacionados con cada una de estas corrientes opositoras, ésta se puede ver en la figura 2:

Fig. 2. Evolución diacrónica de los delitos relacionados con las oposiciones obrera, nacionalista y estudiantil. Fuente: Libros de Sentencias del Tribunal de Orden Público. Elaboración Propia.

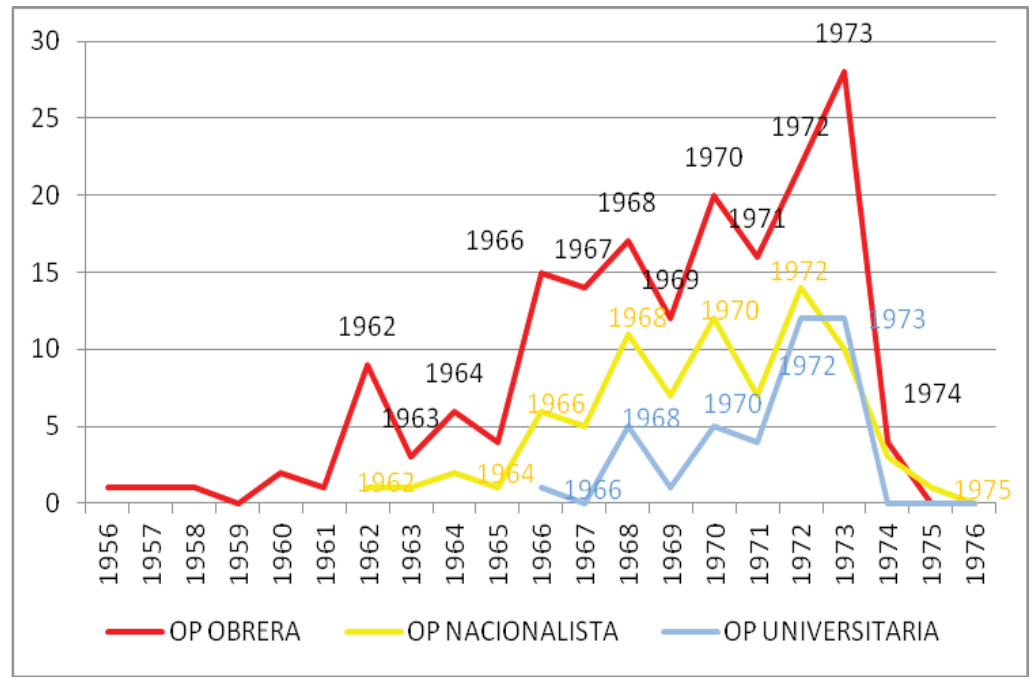


La observación de esta gráfica II pone de manifiesto que además de la más numerosa, la oposición obrera fue también la más antigua y constante, ya que aparece de forma ininterrumpida desde 1956 hasta 1974. En segundo lugar se sitúa la oposición nacionalista, que aparece en 1962 y mantiene presencia hasta 1975. Y en cuanto a la universitaria, ésta no aparece hasta 1966, desapareciendo en 1973, año en que además es muy activa. Este tercer y novedoso tipo de oposición obligó a los gobiernos franquistas "a tomar medidas represivas contra un nuevo modelo de trasgresión política protagonizado por hijos de familias pertenecientes sociológicamente al franquismo" 13 . Ahora bien, aún siendo la de menor presencia, fue también la "que más desestabilizó el régimen y los pilares sobre los que se sostenían puesto que... pusieron en duda el Régimen en su conjunto" 14 .

En lo que coinciden los tres tipos de oposición fue en el final abrupto que tuvieron a partir de 1973, coincidiendo también con la agonía del régimen. Una vez muerto el dictador, los días del Tribunal estaban contados, desapareciendo finalmente en enero de 1977, aunque la última sentencia es de 20 de diciembre de 1976 y los delitos juzgados en esos meses eran de $1975^{15}$.

\section{Retrato de la oposición sentenciada por el tribunal de orden público}

\subsection{Las organizaciones políticas de la izquierda comunista}

La hegemonía dentro de la izquierda opuesta a la dictadura va a pertenecer al comunismo y dentro de éste al Partido Comunista de España. Las sentencias del TOP definen al Partido Comunista de España, como un "ente tendente a la mutación por la fuerza de la vigente estructura estatal española" ${ }^{16}$. Esta oposición protagonizada por el PCE contra el franquismo fue constante, evolucionando "desde la guerrilla a las fábricas" ${ }^{17}$. Ese cambio de orientación en la lucha se produjo entre 1952 y 1961, convirtiéndose a partir de entonces la resistencia política en sindical. Así, el comunismo mantuvo una presencia activa en territorio nacional a lo largo de todos los años de la dictadura. Ello se aprecia perfectamente en la figura 3, en la que se compara el número de sentencias que tuvieron al comunismo como fuerza ideológica encausada, frente a las sentencias que juzgaron a otras corrientes ideológicas, como el socialismo o el anarquismo.

13 VALDELVIRA, Gregorio: La oposición estudiantil al franquismo, Madrid, Síntesis, 2006, p. 227

14 CARRILLO-LINARES, Alberto: "Movimiento estudiantil antifranquista, cultura política y transición política a la democracia", Pasado y Memoria. Revista de Historia Contemporánea, Alicante, 5, (2006), p. 159

15 Para un conocimiento más exhaustivo de ello hay que remitirse a las páginas que del Águila dedica a la supresión del TOP y su transformación en Audiencia Nacional. El autor explica que en el momento de la disolución estaban tramitándose más de quinientos expedientes, entre ellos el incoado a Santiago Carrillo tras su detención en diciembre de 1976. DEL ÁGUILA, Juan José: El TOP ... pp.345-352.

16 Sent. 180, 23 de Junio de 1969, AAPM-TOP, LS 1969-II.

17 RUIZ, David: "De la guerrilla a las fábricas. Oposición al franquismo del Partido Comunista de España (1948-1962)", Espacio, tiempo y forma, Madrid, Serie V, Historia Contemporánea, 13, (2000), p. 112 
Fig. 3. Corrientes ideológicas de la izquierda encausadas en el TOP.

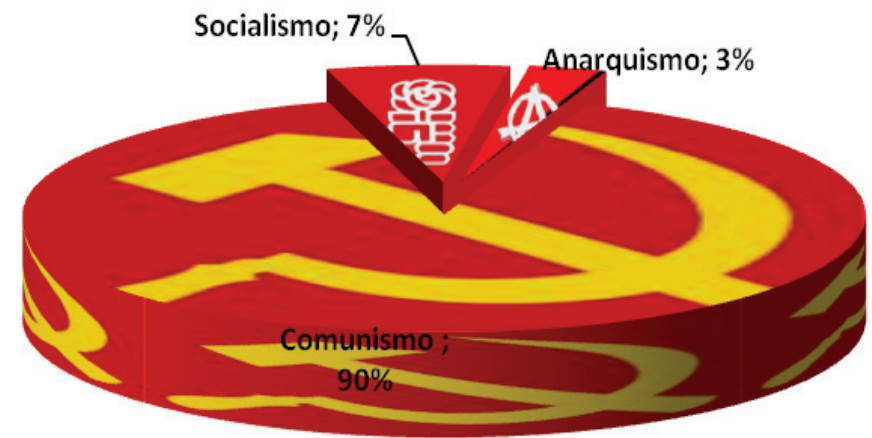

Fuente: Libros de Sentencias del Tribunal de Orden Público. Elaboración Propia.

Y en la figura 4, queda reflejada la preponderancia del Partico Comunista de España, en comparación con otros grupos de adscripción comunista, como el maoísmo o el trotskismo.

Fig.4. Corrientes comunistas presentes en el TOP.

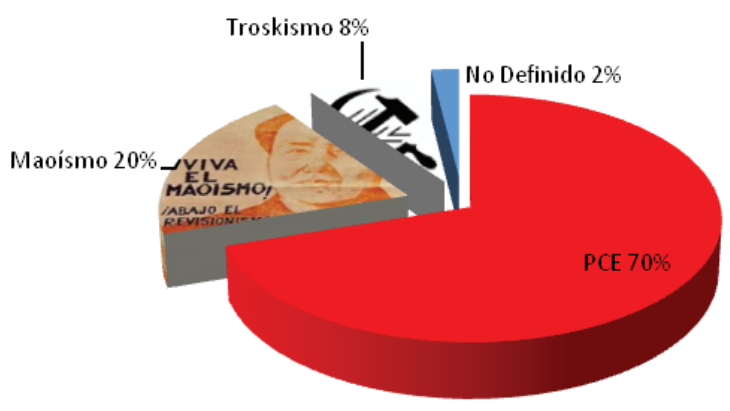

Fuente: Libros de Sentencias del Tribunal de Orden Público. Elaboración Propia

Como se deduce de los datos analizados, el Partido Comunista de España, ya sea acusado directamente, o bien a través de la organización sindical Comisiones Obreras $(\mathrm{CC} . \mathrm{OO})^{18}$, copa un $70 \%$ del total de las sentencias centradas en el comunismo. Es

18 Las primeras Comisiones surgen de manera espontánea en la década de los 50 . Una de las más conocidas fue la surgida en Asturias, concretamente en la mina La Camocha (Gijón) y que protagonizó una huelga. Era el año 1957. Oficialmente como organización sindical, CC.OO surge en 1964 y se presenta a sus primeras elecciones en 1966. 
necesario aclarar que la unión del partido Comunista y Comisiones Obreras ${ }^{19}$ no obedece a un deseo de los autores, sino que se está siguiendo la tendencia y filosofía del propio Tribunal, ya que en las definiciones que las sentencias dan del sindicato es habitual señalar su identidad con el PCE. Así, cuando se hace referencia al sindicato se le define como ".... el ente llamado Comisiones Obreras (...) creado y tutelado por el intitulado Partido Comunista de España..." ${ }^{20}$. Ahora bien, profundizando más en el contenido de las sentencias se llega a la conclusión de que sólo en el 44\% de los casos (de ese 70\% de las sentencias centradas en el Partido Comunista), el PCE y CCOO aparecen juntos. En cuanto a los delitos de los que son acusados sus militantes pueden verse en la figura 5, así como los porcentajes con los que cada uno de dichos delitos aparece.

Fig.5. Delitos protagonizados por el PC-CC.OO.

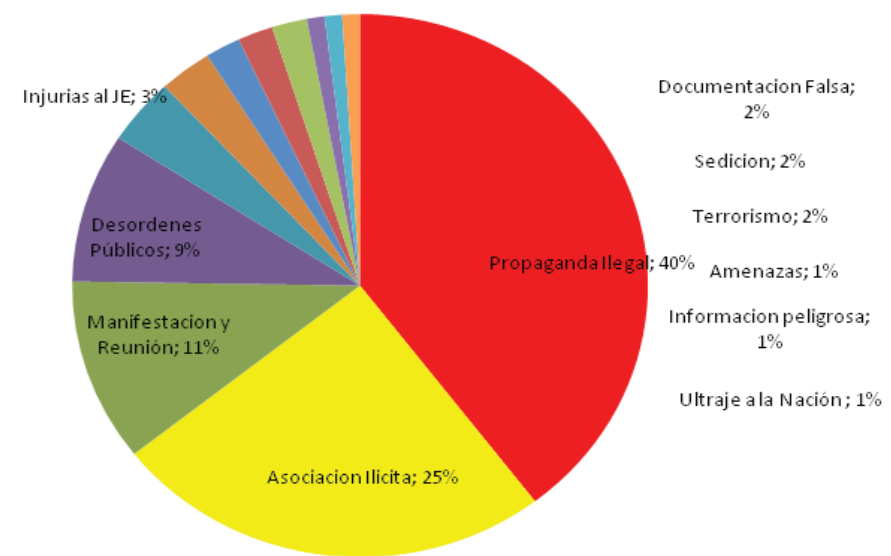

Fuente: Libros de Sentencias del Tribunal de Orden Público. Elaboración Propia.

Lo más significativo en relacion con la tipología de los delitos protagonizados por el PC-CCOO es el predominio del delito de Propaganda ilegal (40\%), seguido por el de asociación ilícita (25\%), lo que da una idea de la fuerte campaña de proselitismo antifranquista llevada a cabo por ambas organizaciones. Igualmente hay que señalar como dato a deducir de lo anterior que la actividad del PCE no aparece habitualmente ligada a acciones violentas o armadas, consignadas en la gráfica como terrorismo, siguiendo también la tipología del propio tribunal, ya que éstas solo aparecen en un $2 \%$ de los casos. Ahora bien, lo que sí existe es una importante actividad callejera protagonizada por sus militantes a través de la celebración de manifestaciones

19 Para el estudio de lo que fue y supuso el Partido Comunista y el surgimiento de CCOO en la lucha antifranquista pueden consultarse JAUREGUI, Fernando, VEGA, Pedro, Crónica del antifranquismo, Barcelona, Planeta, 2007. También puede consultarse lo dicho por Santiago Carrillo en entrevista con Luis Palacios en PALACIOS BAÑUELOS, Luis: El franquismo ordinario. Diálogos con Payne, Carrillo, Mercedes SanzBachiller, Velarde, Tamames, divisionarios, guerrilleros..., Astorga, Akrón,.2011, pp. 183-186.

20 Sent. 205, 07 de Mayo de 1973, AAPM-TOP, LS 1973-II. 
y diversos desórdenes públicos. Este tipo de acciones copa el 20\% de las sentencias analizadas, con lo que se presentan como la tercera causa de enjuiciamiento de los militantes comunistas.

En cuanto al resto de las facciones comunistas, el maoísmo supone un $20 \%$ del total de las causas de ideología comunista. La explicación de esta presencia hay que encontrarla en el hecho de que la muerte de Stalin y la disputa chino-soviética finalmente impactaron en la izquierda española tras el turbulento 1968. El maoísmo revolucionará a la juventud universitaria que se alejó de la ortodoxia e incluso del "complicado" trostkismo para abrazar con fe la utopía maoísta ${ }^{21}$. Los partidos maoístas presentes en las sentencias son los siguientes: El Partido Comunista de España Marxista-Leninista (PCE-ml) que es definido como "el ente que aspira a la mutacion por la fuerza de la vigente estructura estatal española" ${ }^{22}$, aparece en el $44 \%$ de las menciones realizadas al maoísmo. Este partido surgió en 1964 por divergencias con lo que consideraban el viraje heterodoxo que Santiago Carrillo estaba imponiendo al PCE. Por ello aparece por primera vez en las sentencias en 1969, manteniendo su presencia hasta 1974. La acusación habitual para esta formación política es la de asociación ilegítima. De su seno, a su vez, surgiría el grupo terrorista Frente Revolucionario Antifascista Patriótico, el FRAP, que aparece en el 33\% de las sentencias y que se constituyó informalmente en 1971, por lo que es a partir de 1972 cuando se dan los primeros juicios contra ellos en el TOP, quien los define como una "facción del denominado Partido Comunista de España Marxista-Leninista, que tiene como objetivo fundamental, al igual que éste, la mutación de la actual estructura constitucional del Estado Español y que para su logro propugna el uso de la fuerza"23. También en relación con este grupo, la mayoría de las causas abiertas fueron por asociación ilegal, pero con la importante salvedad de que también se encuentran delitos considerados como de terrorismo en un $6 \%$ de las sentencias. Como ejemplo de ello resulta interesante el siguiente extracto de un fallo pronunciado en el año 72: "Probado y así se declara que el 28 de abril de 1972, a últimas horas de la noche, el procesado... de acuerdo con otra persona no identificada en esta causa, se trasladaron andando desde Sardañola a Rubí $(6 \mathrm{~km})$ trasportando en una bolsa que llevaba el primero tres botellas tipo coñac llenas de gasolina que había llevado el segundo. ... sobre las 2 de la madrugada del día 29 se dirigieron al inmueble de la empresa Electrónica JOSA S.A. encendiendo las mechas... arrojando contra puerta y ventana... explosiones,.. vigilantes apagaron el incendio ... desperfectos... 3.075 ptas. deteniendo al procesado y dándose a la huida el otro. Al tiempo de ser detenido portaba una hoja manuscrita en la que se especificaba: $1^{\circ}$ ) Formación técnica; $2^{\circ}$ ) Formación práctica. $3^{\circ}$ ) Formación física. $4^{\circ}$ ) Clandestinidad. $5^{\circ}$ ) Participación en el F.R.A.P.... con expresiones una libreta de fechas, localidades y fábricas" 24 .

En tercer lugar de importancia hay que citar a la Oposición Sindical Obrera (OSO), definida por el TOP como "entidad que siguiendo los postulados del marxismo leni-

21 El maoísmo español, y además analizado desde las sentencias del TOP, tiene un adecuado y acertado estudio en la ya mencionada obra de ROLDÁN BARBERO, Horacio: El maoísmo en España...

22 Sent. 177, 16 de Abril de 1973, AAPM-TOP, LS 1973-II.

23 Sent. 63, 5 de Marzo de 1976, AAPM-TOP, LS 1976-I.

24 Sent. 78, 23 de Febrero de 1973, AAPM-TOP, LS 1973-I. 
nismo opera en la rama laboral" 25 y que aparece en un $11 \%$ de las sentencias encuadradas en el maoísmo, lo que hace de esta organización la segunda en importancia en el ámbito de los sindicatos maoístas ${ }^{26}$. Su presencia cronológicamente se encuadra entre los años 1971-73. Sus afiliados son inculpados, principalmente por asociación ilegal lo que en este caso, además, tiene como consecuencia la desarticulación de sus cuadros. También hay que citar a la Federación Universitaria Democrática Española (FUDE), que fue un sindicato organizado por el PCE en 1961, esta vez desde el interior del sindicato vertical (SEU). El TOP la considera una "facción del intitulado Partido Comunista de España Marxista-Leninista qué al igual que éste y con proyección en el área estudiantil que su nombre indica, persigue la trastocación por la fuerza de la vigente estructura estatal hispana" ${ }^{27}$. En 1967 se adscribió al PCEML. Sus miembros aparecen imputados en el 7\% de las sentencias del maoísmo, normalmente ligados al FRAP, por asociación ilegal. También con protagonismo propio hay que citar a la Organización Revolucionaria de Trabajadores (ORT), que surgió en 1969 de los movimientos obreristas católicos (HOAC) y aparece acusada de los delitos de propagandas ilegales y hurto $^{28}$ en un $4 \%$ de los casos.

Hay que tener en cuenta que tal y como ponen de manifiesto las sentencias del TOP, así como otras fuentes documentales, en la década de los sesenta aparecieron en los ámbitos obreros de oposición al franquismo gran cantidad de sindicatos, en muchas ocasiones sectoriales, regionales y de corto recorrido que dificultan en alto grado su estudio y cuantificación ${ }^{29}$. Por ello se contabilizan muchas apariciones de diversas organizaciones en escala ya muy minoritaria, como es el caso de Acción Revolucionario Unida (ARU), igual que las anteriores es considerada una "facción segregada del PCE marxista leninista, que como éste pretende la mutación por procedimientos de fuerza de la actual organización estatal”30. O también merece la pena señalar el Movimiento Comunista de España o simplemente el Movimiento Comunista. Organización surgida de los sectores más obreristas y españolistas del radicalismo vasco, concretamente de una escisión de ETA V Asamblea en 1966 (ETA Berri/Nueva ETA) que se autodenominó Movimiento Comunista a partir de 1969 y que posteriormente se confederó con otras organizaciones similares del resto de España. El diario $A B C$ de Sevilla, en 1970, muestra anécdótica y a la vez significativamente cómo utilizaba el regimen los medios de comunicación para a través de ellos informar a la sociedad de cuál era el carácter de este tipo de agrupaciones. Llama la atención que la definición que de la ARU da el periódico parece sacada de cualquier sentencia del TOP:

25 Sent. 340, 8 de Julio de 1974, AAPM-TOP. LS 1974-III.

26 Este fue en sus orígenes un sindicato cercano al PCE, que se desarrolló desde dentro de los sindicatos verticales en paralelo a las CC.OO, pero se ha situado en este bloque porque derivó hacia posiciones cercanas al PCEM-L y porque en las sentencias del TOP aparece como sindicato del partido maoísta.

27 Sent. 76, 11 de Febrero de 1974, AAPM-TOP, LS 1974-I.

28 Sent. 342, 8 de Julio de 1974, AAPM-TOP, LS 1974-III.

29 Un estudio que aporta una importante clarificación de las mismas es el de RUIZ, David: "La oposición sindical en el Franquismo: Dispersión y territorialización de las fuentes, Espacio, tiempo y forma, Madrid, Serie V, Historia Contemporánea, 7, (1994).

30 Sent. 454, 28 de Octubre de 1974, AAPM-TOP, LS 1974-IV. 
La organización clandestina ARU (Acción Revolucionaria Unida) fue creada como consecuencia de una escisión del partido comunista marxista-leninista. El motivo de constituirse esta facción se debe a que las cotizaciones realizadas por la base eran aprovechadas con fines lucrativos personales por los responsables del grupo, y cuantas veces fue denunciada esta anomalía, nunca fue tomada en consideración. Por otro lado, consideran al P. C. marxista- leninista poco virulento ${ }^{31}$.

Como en otros movimentos netamente idelógicos también en este grupo de las organizaciones maoístas predomina el delito de propaganda ilegal, que está presente en el $45 \%$ de los casos, seguido muy de cerca por el de asociación ilegal, que aparece en el $42 \%$. Sí es importante señalar que en la mayoría de los casos de asocición ilegal se trata de detenciones de miembros del FRAP. Ya en un porcentaje muy bajo se encuentran los delitos de terrorismo, con un $6 \%$ de presencia en las sentencias. Y a continuación les siguen los delitos de manifestación y de desordenes públicos, con un $3 \%$ cada uno. Independiente del grado de presencia de cada delito, lo que estas cifras ofrecen es una clara idea de que el maoísmo fue un movimento muy activo.

En último lugar de este apartado se encuentra el grupo dedicado a los delitos protagonizados por el trostkismo. Esta ideología había sido adoptado como referente por un grupo de comunistas heterodoxos antes del florecimiento del maoísmo ${ }^{32}$. La corriente trotskista significa en la muestra el $8 \%$ de las sentencias de la izquierda revolucionaria. A diferencia del maoísmo, en este caso el delito más representado es el de asociación ilegal, con el $41 \%$ de las sentencias, seguido del de propaganda ilegal, que se queda en el 35\%. El resto de los delitos presentes (terrorismo, atentado o tenencia de armas) no superan el $6 \%$. Como curiosidad aparece un delito hasta hora no presente, como es el de la violación de secretos, que también está presente en el $6 \%$ de los casos. Ahora bien, a pesar de esta variación, sigue siendo válida la afirmación de que entre la extrema izquierda existía tanto identidad en las actuaciones como en la represión de las mismas. El TOP así lo explicita cuando se refiere a los fines de estas organizaciones:

...que no son otros que la implantación de la dictadura del Proletariado con derrocamiento por la fuerza del actual sistema estatal, "gobierno revolucionario que sea el representante de las organizaciones que hayan llevado a cabo el derrocamiento del franquismo"(sic) e identificado con ellos en la denominada Liga Comunista Revolucionaria, organización encuadrada dentro del Partido Comunista Internacional formando parte del llamado Comité Revolucionario de la parte izquierda del Nervión, Sestao a Zorroza... actuaban en la orilla izquierda del Nervión a la que llamaban Liverpool... ${ }^{33}$.

Las organizaciones trostkistas que se han aprecido en la muestra vienen encabezadas por la Liga Comunista Revolucionario (LCR), presente en el 40\% de las senten-

$31 A B C$ de Sevilla, 6/02/1970, p. 43.

32 Para conocer cómo el trotskismo fue superado por el maoísmo con una imagen más radical y juvenil puede consultarse la obra de GARCÍAALCALÁ, Julio Antonio: Historia del "Felipe": (FLP, FOC E ESBA):de Julio Cerón a la Liga Comunista Revolucionaria, Madrid, Centro de Estudios Políticos y Constitucionales, 2001.

33 Sent. 289, 19 de Junio de 1973, AAPM-TOP. LS 1973-III. 
cias. Este partido fue fundado en 1971 por jóvenes catalanes procedentes del Frente de Liberación Popular (FLP, también conocido como "Felipe"). En 1973 se fusionó con una nueva excisión de ETA, ETA VI Asamblea, renunciando al terrorismo y tomando un protagonismo muy significativo en el País Vasco. En diversos procesos fue juzgado conjuntamente con el Partido Obrero Revolucionario. A ambas organizaciones el TOP las consideraba "de carácter trotskista que siguen la línea de la IV Internacional pretendiendo el derrocamiento de las actuales estructuras estatales..." ${ }^{34}$. Dicho Partido Obrero Revolucionario (PRT o PORE), está presente en las sentencias del TOP en un $20 \%$ de los casos, encausado por delitos consumados en 1968. Es importante poner de manifiesto que en las sentencias analizadas en la muestra el propio tribunal tenía muchas veces problemas para definir claramente las relaciones entre las diversas organizaciones de extrema izquierda que surgían en el tiempo. Este problema de identificación ideológica se debió a la atomización de esta extrema izquierda en la que los grupos nacían, se disolvían y fusionaban con mucha facilidad. Así, aunque según diversos estudios publicados el PCI se indetificaba con el PCE-I, que a su vez era la base fundadora del PTE y que había surgido de una excisión maoísta del PSUC en 1967, en las sentencias del TOP el PCI aparece siempre como elemento aglutinador del PCEML y de la LCR, así como de otras organizaciones minoritarias ${ }^{35}$.

Finalmente, para terminar este apartado, en la figura 6 puede observarse la evolución diacrónica de dichas organizaciones y sus delitos. En ella se pone de manifiesto que el PCE es la gran fuerza aglutinadora de la izquierda revolucionaria y que la reactivación de los movimentos trostkistas y maoístas se produjo al final de la década de los sesenta, cuando las mutaciones de la sociedad española y la quiebra ideológica del comunismo internacional hicieron proliferar una mayor diversidad partidista

Fig. 6. Evolucion diacrónica de las corrientes comunistas. Fuente: Libros de Sentencias del Tribunal de Orden Público. Elaboración Propia.

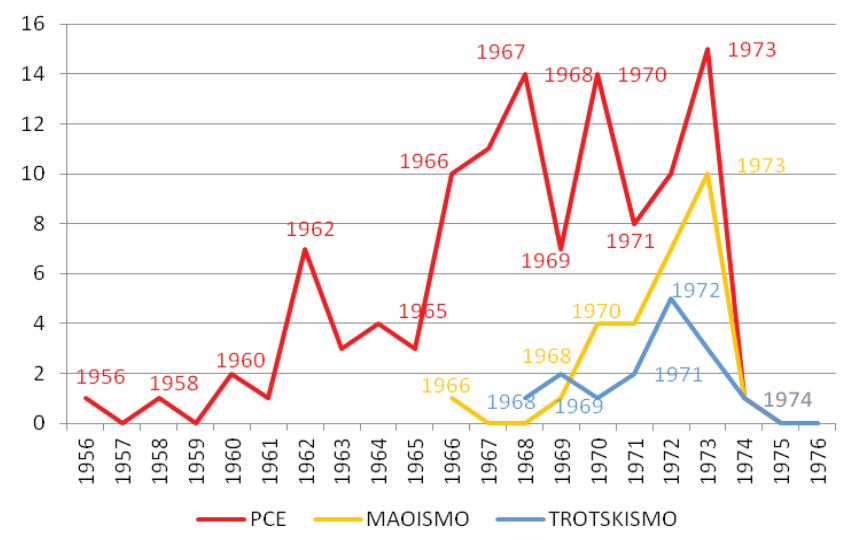

34 Sent. 401, 22 de Octubre de 1973, AAPM-TOP, LS 1973-IV.

35 Para un estudio en profundidad de los grupos trotskistas es interesante consultar la obra de MANTÉ COT, Roser: Formación y evolución del Partido Comunista de España (Internacional) PCE (i) 1968-1973, [en línea] Barcelona, UAB, 2004. Disponible en: http://www.pte-jgre.com/historia/Historia $\% 20 \mathrm{del} \% 20$ PCE(i).pdf y también la de PEREDA, Rosa: Contra Franco, 1968-1978, Barcelona, Planeta, 2003. 


\subsection{El socialismo y el anarquismo}

El socialismo, representado por UGT y PSOE, aunque a mucha distancia de las organizaciones comunistas, constituía la segunda gran corriente de la oposición de izquierdas. Concentra el 7\% de las sentencias contra la izquierda. Como dato curioso se ha constatado que sólo en un $60 \%$ de los casos aparece en solitario, estando en el $40 \%$ restante asociado al comunismo o al nacionalismo. Lo más destacado desde el punto de vista histórico es que su presencia queda circunscrita al norte de España, principalmente Asturias. Y también es significativo que practicamente la mitad de las sentencias hacen referencia a los contactos existentes con la cúpula instalada en el exilio. Otra cuestión destacable es que el análisis de las sentencias demuestra que las autoridades fueron conscientes de que desde el inicio de la década de los 70 hubo importantes intentos de revitalizar a la UGT, con el fin de contrarrestar por parte del socialismo el protagonismo que CC.OO estaba adquiriendo en el universo del sindicalismo español, a través de su estrategia de infiltración en los sindicatos verticales franquistas.

Las causas contra el socialismo se centran fundamentalmente en la represión de los delitos de asociación ilicita (42\%) y propaganda ilegal (42\%). Minoritariamente también hay sentencias dedicadas a enjuiciar delitos de manifestaciones no pacíficas (7\%) y otros delitos.

Por lo que se refiere al anarquismo, no puede olvidarse que como corriente ideológica activa desapareció prácticamente después de la guerra civil. Consecuentemente con ello tiene apenas una presencia anecdótica, pues sólo aparece en el 3\% de las sentencias referidas a las actividades de la izquierda. Aunque también se desprende del análisis realizado que existieron intentos por reactivar la CNT y sobre todo destaca el protagonismo de la trágica aventura del MIL "Movimiento de Ibérico de Liberacion" de Salvador Antich y sus amigos barceloneses. Para el TOP una "... de tendencia anarquista, que persigue entre sus principales metas, el derrocamiento de la vigente estructura estatal hispana, mediante el empleo de acciones violentas que sus miembros realizan en grupusculos denominados 'de comando'..." ${ }^{36}$. Los delitos por los que son juzgados se produjeron a patir del año 1971 y se concetran en asociación y propaganda ilegales, constatándose la desarticulación de la organización en 1973.

\subsection{Los nacionalismos}

El nacionalismo es la segunda gran corriente ideológica presente en los grupos activos de oposición que se enfrentan al franquismo. Protagoniza un $23 \%$ de los delitos juzgados en el TOP, aunque no en todos los casos estudiados tiene un protagonismo judicial claro, ya que su presencia en diversas sentencias se encuentra presente a través de textos y manifestaciones de solidaridad que con el nacionalismo realizan los grupos de izquierda. El caso más emblemático es el Juicio de Burgos ${ }^{37}$.

\footnotetext{
36 Sent. 523, 29 de Noviembre de 1974, AAPM-TOP, LS 1974-IV.

37 "Probado y declarado que sobre las 21.00 h. del día 12 de diciembre de 1970, en Langreo, los procesados Julio Alberto Macías Noval y Esteban Gil Grova Velasco, se dedicaron a pegar en coches, lunas de escaparates, cartelera de los cines y en el portón de la empresa Uninsa, en las calles de la Felguera unos pasquines
} 
En este bloque ideológico de oposición, como se comprueba en la figura 7, la hegemonía del nacionalismo vasco es absoluta y su protagonismo se patentiza tanto por su presencia directa como indirecta, copando un $79 \%$ de las sentencias.

Fig.7. Los movimientos nacionalistas presentes en el TOP.

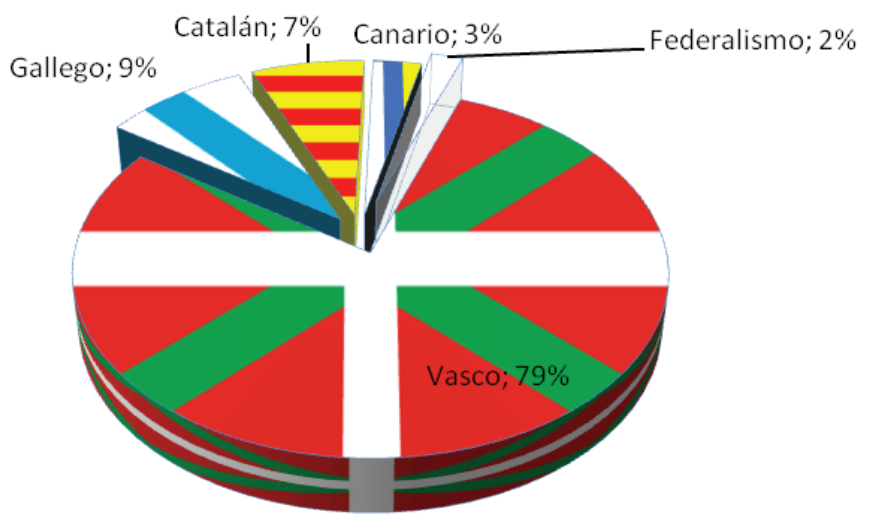

Fuente: Libros de Sentencias del Tribunal de Orden Público. Elaboración Propia

Dentro del nacionalismo vasco, la hegemonía corresponde a ETA, que tiene el protagonismo en el $67 \%$ de los delitos de que es acusado el nacionalismo vasco. Junto a ésta, con el $9 \%$ de las sentencias, aparecen otras organizaciones independentistas como EGI (Fuerza Juventud Vasca), FNV Frente Nacional Vasco) y STV (Sindicato de Trabajadores Vascos). Llama la atención la escasa presencia del PNV, con tan sólo el $2 \%$, que se explica de porque el PNV, si bien mantuvo su gobierno en el exilio, casi no tuvo presencia en el territorio nacional, salvo a través de sus organizaciones juveniles ${ }^{38}$. Aparece también, aunque de manera puntual, la Alianza Sindical de Euskadi "integrada por facciones procedentes de la Confederación Nacional del Trabajo, de la Unión General de Trabajadores y Solidaridad de Trabajadores Vascos", según explica la propia sentencia del TO" 39 . Finalmente, es preciso aclarar que existen una serie de sentencias relativas a organizaciones de la extrema izquierda vasca, que normalmente han surgido de escisiones de ETA y que en muchos casos se incorporaron al MLNV y

engomados que tenían los siguientes textos: ¡Libertad para los procesados de Burgos! ... el también procesado Enrique Fueyo Vega, el cual, a la mañana del día siguiente, reiteró al entrega de 150 hojas, impresas a ciclostil, ... En las citadas hojas, suscritas por Juventudes Comunistas de Langreo y fechadas en Diciembre de 1970, cuyos textos conocían los procesados, se insertan frases del siguiente tenor: "Franco le prepara a España unas Navidades sangrientas. El juicio de Burgos... llega al desenlace lógico que la brutalidad del dictador le había fijado... El régimen no tiene más apoyo que esos verdugos con sus porras y sus pistolas, que no hay una base social y política que le sustente. Esa sangre clama justicia, como lo claman los muertos de Erandio y Granada...". Sent. 211, 6 de Julio de 1971, AAPM-TOP, LS 1971-II.

38 La única vez que aparece el PNV en la muestra es relacionado con la detención de unos militantes que preparaban los actos del Aberri Eguna (Sent. 186, 21 de Junio de 1971, AAPM-TOP, LS 1971-II)

39 Sent. 93, 6 de Agosto de 1966, AAPM-TOP, LS 1966-I. 
que no han sido incluidas en el computo porque dado su ideología de extrema izquierda, fueron contabilizadas con el grupo ideológico de la extrema izquierda.

Sí es importante señalar que la organización ETA, que tan marcado y dilatado protagonismo alcanzará en años posteriores, en sus inicios creó confusión en las autoridades judiciales franquistas a la hora de identificarla y definirla adecuadamente. Así, en las primeras sentencias a ella dedicadas se la define como “....asociación clandestina de matiz separatista vasco E.T.A. (Euzkadi ta Azkatasuna)...”. Lo anterior se redimensiona mejor si se tiene asimismo en cuenta el contexto de dicha sentencia, ya que es el resultado del juicio celebrado contra Javier Imaz Garay, uno de los fundadores de ETA, por un delito de desórdenes públicos cometido el 17 de febrero de $1964^{40}$. Avanzando en el tiempo, también se profundizará en el conocimiento y definición de ETA, definiéndola ya al final del franquismo como una organización que "entre sus objetivos pretende, principalmente, la secesión de una parte del territorio nacional para su constitución en unidad política independiente del Estado Español, empleando para ello, medios y procedimientos no pacíficos" 41 . En cuanto a los delitos por los que son juzgados los miembros de ETA destaca, muy por encima del resto, el de asociación ilícita (58\%); seguido por el propaganda ilegal, (14\%), desorden público $(10 \%)$, terrorismo y tenencia de armas $(6 \%)$ y manifestación ilegal y amenazas (3\%). Aunque en principio pudiera parecer extraña la escasa presencia de los delitos considerados como terrorismo, ello se explica porque los delitos de sangre con causa política no eran competencia del TOP, sino que correspondían a la jurisdicción militar según el decreto de 21 de septiembre de 1960, que establecía que los casos de rebelión militar, terrorismo y bandidaje quedaban confinados dentro de la competencia de tribunales militares, quienes los juzgarían mediante la fórmula de Consejos de Guerra. En 1971 esta legislación se derogó ya que el Código de Justicia Militar fue reformado. A partir de entonces, dichos delitos estarían recogidos en el mismo, a la vez que se estableció un endurecimiento de las penas correspondientes, llegando al establecimiento de la pena de muerte para los casos juzgados por asesinato.

Lo que demuestran, tanto el contenido de las sentencias analizadas, como la distribución delictiva, es que ETA tenía una importante capacidad proselitista, como se comprueba por los casos de asociación ilícita y propaganda ilegal. También se pone de manifiesto que contaba con un amplio respaldo en el País Vasco como se deduce de los casos de manifestación y desórdenes. Además aparece reflejada la existencia de simpatías hacia la organización fuera del País Vasco, ya que un 16\% de las menciones que se encuentran a ETA en las Sentencias del TOP analizadas se refieren a la simpatía que el movimiento secesionista vasco levantaba entre la izquierda española. Ahora bien, hay que tener en cuenta que la mayoría de estas alusiones de solidaridad con ETA por parte de la izquierda española se realizan en el contexto del conocido como Juicio de Burgos ${ }^{42}$.

40 Sent. 37, 7 de Abril de 1964, AAPM-TOP, LS 1964-I.

41 Sent. 66, 6 de Febrero de 1974, AAPM-TOP, LS 1974-I.

42 El juicio de Burgos, se celebró entre el 3 y el 28 de diciembre de 1970. Los inculpados fueron 16 miembros de ETA acusados de tres asesinatos, más otros delitos menores como encubrimiento, atentados y robos. Recuérdese que el Decreto del año 1963 había abierto la posibilidad de que los tribunales civiles juzgasen los delitos políticos, pero con la muerte del comisario Melitón Manzanas (agosto de 1968) y el Estado de 
Junto a la organización terrorista ETA, en las sentencias analizadas también aparece la organización EGI, que era la rama juvenil del PNV y que era definida por el TOP como una "entidad vasca clandestina (...) que persigue como objetivo la desmembración del conjunto hispano, de determinadas provincias proponiendo para ello la utilización de métodos de fuerza..." ${ }^{43}$. En tercer lugar, también es juzgada "Solidaridad de Trabajadores Vascos (STV), asimismo considerada por el TOP "de carácter secesionista» ${ }^{44}$.

El otro nacionalismo que alcanza un cierto protagonismo en las sentencias (el 9\%) es el gallego, lo que se explica no tanto por un arraigado e histórico sentimiento nacionalista del los gallegos, como por el hecho de que estos grupos mantienen una íntima relación con la extrema izquierda españolista. Así, aparecen conjuntamente militantes del PCE, del PCEML y del Partido Comunista de Galicia ${ }^{45}$. Con menos presencia, ya que solo aparece en el 3\% de los casos, se encuentra el nacionalismo canario. Pero a pesar de tan escasa representación, es necesario hacer una referencia al mismo por la particularidad que presenta por tener contactos con servicios secretos extranjeros ${ }^{46}$. Así lo pone de manifiesto una sentencia de 1971 en la que se dice:

Probado y así se declara que [BERNARD MARIO LEDOUX -DENISE JOUSEPHINE BOURLES, ambos nacidos en Argelia].... de nacionalidad francesa ... llevaban bajo el asiento trasero de un vehículo Peugeot ... a las 7 de la tarde de 1970 con ánimo de hacerlas circular por territorio hispano... 480 cuartillas multicopistas en diversos idiomas entre ellos español titulado "¿Va ud. a España?... 75 pegatinas con ¿Viva Canarias Libre? ... 92 folios con "Movimiento por la Autodeterminación y la Independencia del Archipiélago Canario". ... turistas frente a cientos de hombres en calabozos... Canarias no es España... nuestro archipiélago es la presa de los españoles... nuestra amada patria tendrá que ser arrancada por la fuerza... por la vía pacífica no conseguiremos nada... ${ }^{47}$.

Por último y quizás lo más llamativo de todo, es la escasísima presencia del nacionalismo catalán, que es el menos representado de todos en las sentencias analizadas. Las pocas veces que aparece es a través del PSUC y sólo en relación con el lanzamiento de proclamas catalanistas. Una posible razón que explica esta circunstancia es que la actividad del nacionalismo que posteriormente tomaría las riendas de la Cataluña democrática discurría entonces por cauces de tipo más culturales, lo que llevará a que si bien aparezca entre 1970 y 1973, lo haga sólo relacionado con el delito de propaganda ilegal y en menor medida con el de asociación ilícita ${ }^{48}$.

excepción consiguiente, desde el 6 de agosto de 1968, la jurisdicción militar se hizo cargo de nuevo de los asuntos políticos. A partir de esa fecha, la Capitanía General de Burgos tomó las riendas de todas las cuestiones relacionadas con el orden público en el País Vasco.

43 Sent. 199, 2 de Mayo de 1973, AAPM-TOP, LS 1973-II.

44 Sent. 235, 22 de Mayo de 1973, AAPM-TOP, LS 1973-II.

45 Sent. 168, 7 de Junio de 1969, AAPM-TOP, LS 1969-II.

46 Recuérdese que son los años posteriores a la independencia de Argelia y su proselitismo norteafricano

47 Sent. 247, 11 de Octubre de 1971, AAPM-TOP, LS 1971-III.

48 Para ampliar este tema es interesante el estudio ya citado de la Fundación Cipriano García, TÉBAR, Javier (Coord.). Topcat 1963-1977.... En su exhaustivo análisis de la actividad del TOP contra personas y organizaciones catalanas o residentes en Cataluña se encuentra el listado de organizaciones políticas catalanas a 


\subsection{La oposición universitaria}

Coincidiendo con el importante trabajo ya citado de Valdelvira ${ }^{49}$ sobre la oposición estudiantil al franquismo, en nuestro estudio queda también reflejado que la oposición estudiantil estaba alimentaba mayoritariamente por movimientos de izquierdas ${ }^{50}$. En concreto, un 53\% de las apariciones de la universidad en las sentencias están relacionas con el comunismo, frente al $17 \%$ en el que aparece reflejada una conexión con el nacionalismo, aunque la tipología de los incidentes en ambos casos es muy similar: algún problema docente actúa como detonante y se termina con altercados y manifestaciones no pacíficas ${ }^{51}$. En el $30 \%$ restante no se pueden sacar conclusiones de la adscripción ya que en todas esas sentencias el Tribunal, a la hora de redactar el fallo, suele mostrarse muy ambiguo y no define claramente cuál es la ideología que motiva los disturbios, dejándolos conscientemente en la sombra, tal y como se demuestra en el siguiente ejemplo:

Probado y así se declara, que en la mañana del día 26 de enero de 1972, los procesados Gerardo Frontells Avellana, Eduardo Otero Ledesma, Eduardo Griñó Sayrol, Antonio Manuel Tufet Esteve, con conocimiento de la carencia de autorización gubernativa, se unieron a un numeroso grupo de unas doscientas personas que discurrieron por la Avenida de José Antonio de Barcelona, paralizó temporalmente el tránsito rodado y alteró la normalidad callejera ${ }^{52}$.

Como el caso anterior, la mayoría de los delitos por los que los universitarios son encausados es el de la manifestación no pacífica (29\%). Al que se suman desórdenes Públicos (13\%) y reunión ilegal (7\%). A esta conjunto se unen también los juicios celebrados en torno a los delitos atentado/lesiones (11\%), pues casi siempre ocurren en los momentos de la detención. En total suman un $60 \%$ de los casos. El otro gran delito por el que los estudiantes son juzgados en el TOP es el de propagandas ilegales

las que pertenecían los imputados. Asimismo y bajo la coordinación del mismo Javier TÉBAR se recomienda el libro recientemente publicado por la Universidad de Valencia, Resistencia ordinaria. La militancia y el antifranquismo catalán ante el Tribunal de Orden Público, 1963-1977 (Valencia, 2012) que sobre la base del estudio anterior profundiza en el estudio del antifranquismo y donde el propio Tébar hace referencia al cambio que tanto la militancia antifranquista como las autoridades del régimen experimentaron con el paso del tiempo. También merece ser consultado el trabajo de DOVAL, Gregorio: Los últimos años del Franquismo (19691975). Todo quedará un día atado y bien atado, Madrid, Síntesis, 2007, donde se pueden contrastar la apuesta culturalista de Jordi Pujol como representante más acabado de la burguesía catalana y la hegemonía del PSUC en los ámbitos de la juventud catalanista.

49 VALDELVIRA, Gregorio: La oposición estudiantil

50 Carrillo-Linares habla de tres círculos concéntricos en el movimiento estudiantil dependiendo del grado de compromiso de los universitarios: un núcleo duro controlado por los partidos; un grupo de colaboradores politizados pero no afiliados y una masa que se suma a las movilizaciones con independencia de quien las organice o protagonice. CARRILLO-LINARES, Alberto: "Movimiento estudiantil antifranquista...

51 "Probado y así se declara, que aglutinando un número considerable de personas, en su mayoría estudiantes, superior a doscientas, el día 22 de febrero de 1973, a las 20,30 horas, por el paseo Primo de Rivera de Sabadell, profiriendo gritos y lanzando octavillas sobre cuestiones docentes, discurrieron por aquella avenida, siendo detenidos en las inmediaciones, sin que conste su participación en la aludida concentración humana, los imputados.... Mayores de 16 y menores de 18...". Sent. 172, 1 de Abril de 1974, AAPM-TOP, LS 1974-II.

52 Sent. 170, 13 de Abril de 1973, AAPM-TOP, LS 1973-II 
(22\%). Estos casos no suelen estar relacionados con el conjunto anterior, sino con el tercer delito por el que lo estudiantes son encausados, el de asociación ilícita (13\%).

El restante porcentaje corresponde a delitos minoritarios llevados a cabo por universitarios, pero sin relación directa con la Universidad. En la gran mayoría de los casos siempre se inculpa a una sola persona (42\%) o como mucho a dos $(20 \%)$ o tres (20\%). En estos casos de acusaciones conjuntas se suele comprobar la existencia de relaciones afectivas, familiares o de amistad entre los inculpados. Relacionado con esto, se debe destacar que un $22 \%$ de los estudiantes inculpados son mujeres.

Por estudios o carreras las sentencias dejan ver un gran protagonismo de las Universidades Laborales, especialmente en la rama de Maestría Industrial (14\%) y de las Facultades de Medicina (12\%), seguidas de las de Económicas, Ciencias Políticas y Filosofía y Letras. En un tercer peldaño de politización estarían Arquitectura, Fiscales, Ingenierías y Químicas. Finalmente, un 9\% de los casos corresponde a otros estudios, como colegios y academias. Ahora bien, hay que tener en cuenta que en el $31 \%$ de los casos las sentencias no especifican a qué facultad pertenecen los inculpados o en qué edificio se llevó a cabo el delito, refiriéndose sólo a la universidad en sentido genérico. Por ello la extrapolación de cifras anterior es exclusivamente aproximativa.

Si se analizan las sentencias desde el prisma de la ubicación geográfica, los centros universitarios que presentan una mayor actividad opositora al régimen son los catalanes, copando el $40 \%$ de los casos y casi doblando la presencia de las universidades madrileñas, que sólo alcanzan el $22 \%$. Por su parte, Bilbao aparece en una proporción del $11 \%$. A este triangulo básico habría que sumar Zaragoza (8\%) como cabeza de una actividad opositora, aunque de menor proporción. Lo que sí parece, aunque con presencia relativa o incluso escasa, es que la oposición universitaria al régimen está ampliamente generalizada y diversificada por el territorio, ya que en la muestra aparecen protestas e incidentes en diversas provincias Valladolid, Córdoba, Sevilla, Gijón, Santiago, La Coruña y Valencia.

En cuanto a los fallos condenatorios o absolutorios, la relación es mucho más equilibrada que en el conjunto de los casos juzgados en el TOP. En concreto las sentencias de culpabilidad suponen un 53\% frente al $47 \%$ de absoluciones.

\section{Comparativa de resultados con estudios previos}

Dado que el planteamiento de origen difería de estudios anteriores, resulta interesante para comprobar la validez de los resultados obtenidos realizar comparativas con el estudio previo sobre el TOP más exhaustivo, el elaborado por del Águila. Así, en la figura 8, se comparan el número de sentencias por año (según el estudio de J. J. del Águila) y el número de delitos según la metodología aquí aplicada. Así, se observan las diferencias y similitudes que se originan por la aplicación de una u otra manera de aproximarse al mismo objeto de estudio. 
Fig. 8. Delitos frente a sentencias en el TOP. Fuente: Elaboración Propia a partir de los Libros de Sentencias del Tribunal de Orden Público y los datos obtenidos del trabajo de J. J. Del AGUILA.

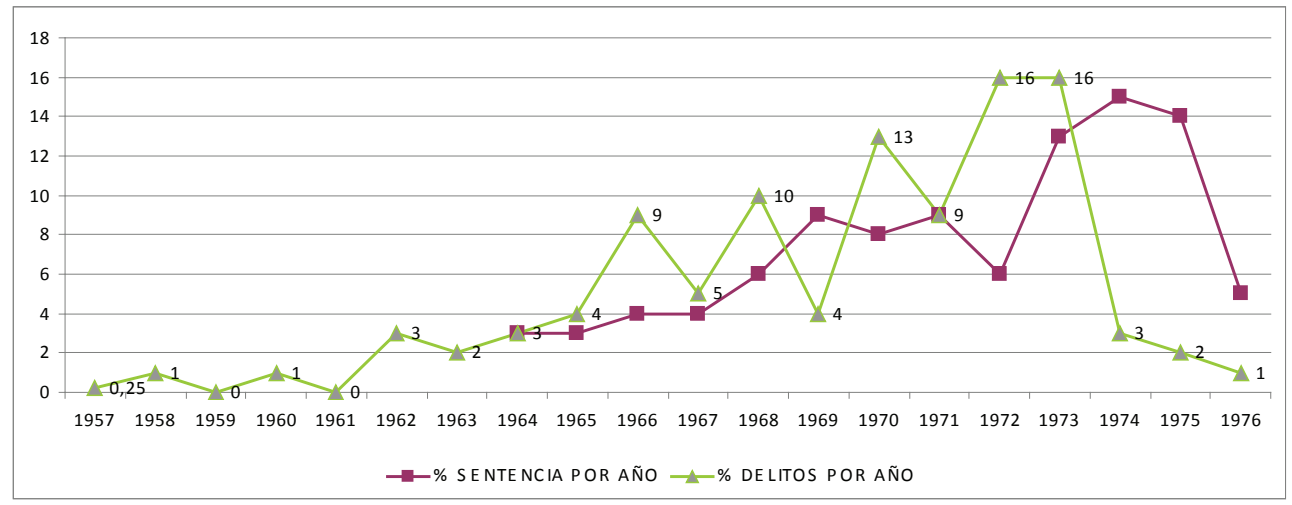

En ambos casos se constata el incremento constante de los delitos desde 1957 y su abrupta interrupción a partir de 1973, aunque los juicios con causas procedentes de años anteriores siguieron creciendo hasta 1974, se mantuvieron en 1975 y tuvieron un final rápido, casi de colapso, en el ya epilogar 1976. Asimismo, de la lectura de la gráfica y en relación con los datos obtenidos, se observa también que los años en los que se produjo una mayor comisión de delitos son, por orden descendente: 1972, 1973, 1970, 1968, 1971 y 1966. Contabilizados globalmente acaparan el 73\% del total de los delitos. Y en cuanto a la diversidad de los delitos la gráfica pone de manifiesto que los años de mayor variabilidad delictiva fueron, también en orden descendente: 1972, 1966, 1971 y 1968.

El hecho de que, grosso modo y aunque las metodologías aplicadas hayan sido diferentes, haya una importante coincidencia de años entre ambos estudios, avala la validez y efectividad de la metodología aplicada. Validez y efectividad que se puede ver de manera más clara en las figuras 9 y 10 :

Fig. 9. Distribución de figuras delictivas por sentencias (metodología de Del Águila). Fuente: J. J. Del AGUILA, El TOP. La represión de la libertad (1963-1977).
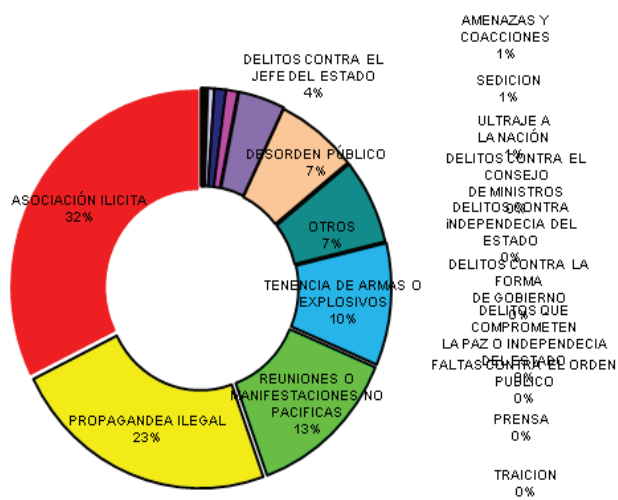
Fig. 10. Distribución de delitos (metodología de los autores). Fuente: Libros de Sentencias del Tribunal de Orden Público. Elaboración Propia.

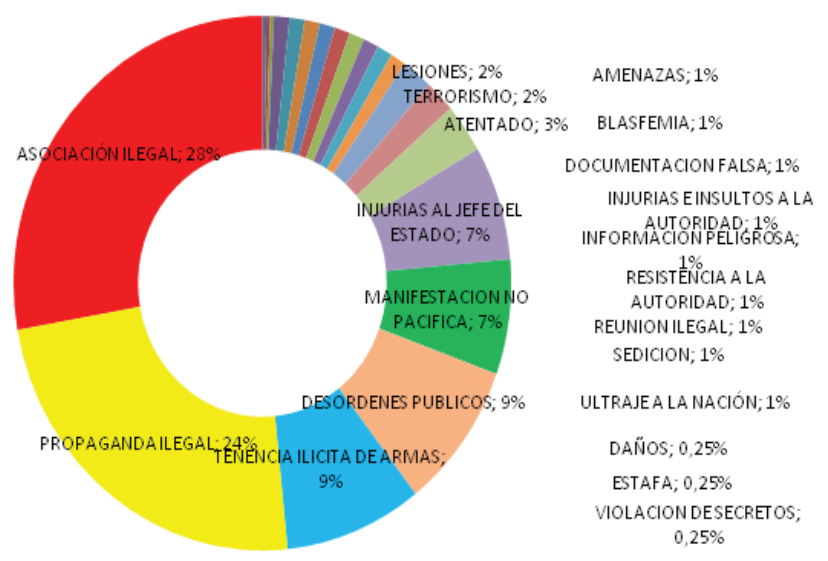

Como se puede observar, ambas gráficas son muy similares, con diferencias porcentuales de un 2 o 3\% y alguna variabilidad en cuanto a la denominación de algunos delitos. Por ejemplo, reuniones o manifestaciones no pacíficas son $13 \%$ en el trabajo de J. J. del Águila y en el aquí presentado representan un 9\%. La variación se debe, además de al cambio metodológico, a las sutilezas de nomenclatura utilizadas por las autoridades franquistas. Asimismo, si se suman desordenes públicos, manifestaciones y reuniones ilegales, tal y como aparecen diferenciados por del Águila, se obtiene un total del $20 \%$, lo que supone sólo un $2 \%$ más de lo obtenido según el cómputo aplicado en esta investigación. Un último apunte, en ambas cuantificaciones aparecen la asociación y propaganda ilegales como los delitos hegemónicos, ya que constituyen el 55\% en el caso de Del Águila y 52\% de los delitos en el de los autores.

\section{Conclusiones}

Finalizado el análisis al que se han sometido los delitos recogidos en las sentencias del TOP, se puede afirmar que la oposición que más preocupaba al franquismo era la encabezada por el movimiento obrero, con un 53\% de los casos. La oposición nacionalista, fundamentalmente vasca, copó el $23 \%$ de las acciones opositoras y la oposición universitaria, que tanto debilitó al régimen, curiosamente, ocupa un tercer lugar, con un $15 \%$ de los delitos juzgados en el TOP.

En cuanto a las organizaciones políticas que estaban detrás de aquellos movimientos sociales, la oposición al franquismo estaba encabeza y organizada en torno al Partido Comunista de España y otras organizaciones de segundo orden pero también con claro signo comunista, seguida por un heterogéneo conglomerado de nacionalismo vasco liderado, a su vez, por la naciente Euskadi ta Azkatuta. Corrientes ideo- 
lógicas todas ellas, a excepción de la ETA, que están presentes también en una parte importante de las sentencias referidas al movimiento estudiante (el 70\% de ellas).

Lo que es llamativo es el hecho de que una amplia mayoría de los delitos juzgados se refieran a cuestiones de propaganda ilegal y asociación ilícita, sin profundizar realmente en aquellos comportamientos que sí fueron permitiendo que la oposición que actuaba en el interior fuese organizándose y preparándose para el cambio de régimen que cada vez estaba más próximo.

En definitiva, un cuadro clarificador que si bien por una parte confirma lo que históricamente se sabe, deja también, aún hoy más de treinta años después, una serie de preguntas abiertas. Por ejemplo: el hecho de que las autoridades franquistas se centrasen tanto en perseguir cuestiones de imagen y de opinión, ¿cuántos espacios libres dejó para que un aprovechamiento adecuado de ellos permitiese madurar a esa misma oposición? O bien, ¿hasta qué punto el hecho de que el principal delito, de por ejemplo el PC, fuera el de la propaganda ilegal y el de ETA el de asociación ilegítima, muestra una manera diversa de actuación y de consiguiente represión que tendrá traducciones evidentes y palpables (positivas y negativas) una vez que se establezca un sistema democrático? Preguntas todas ellas que abren el camino a investigaciones posteriores que a partir de considerar el delito como objeto de estudio, puedan profundizar en las implicaciones reales que una lucha contra la oposición muy cruenta, pero a la vez tan poco sistemática y en algunos casos casi errática, ya que no entraba en el corazón de las acciones, sino que se quedaba en la superficie de las mismas, favoreció, o no, el desarrollo de los movimientos de oposición y su posterior evolución en los últimos momentos de la dictadura e incluso después de la muerte del dictador.

Más allá de los interrogantes abiertos, esta forma de estudio que tiene al delito como elemento central pone de manifiesto varias cuestiones: primero, lo importante es el número de delitos y no el de sentencias, entre otras cosas porque en una misma sentencia se han podido enjuiciar varios delitos. Segundo, lo relevante históricamente es la fecha de comisión del acto punible -que representa la realidad social-y no la de la sentencia, que puede haberse fallado entre uno y cuatro años después de cometido el delito. Por ejemplo, aunque en la sentencia No 260 de 1969 fechada el 13 de octubre, en su encabezamiento sólo aparece un delito asociación ilícita, cuando se lee la sentencia completa se comprueba que se trata de una serie de los mismos delitos cometidos en 1962, 1964, 1965, 1966, 197 y 1968 (Sent. 260, 13 de Octubre de 1969, AAPM-TOP, LS 1969-III). Tercero, se ha conseguido ampliar el periodo estudiado más allá de su cronología limitadora, ya que, por ejemplo, sentencias correspondientes al año 1964, enjuiciaban delitos de 1956. Y cuarto, la forma de aproximarse al objeto de estudio ha servido también para observar con mayor claridad cuáles son los años de mayor tensión social y represión estatal. 